\title{
LASER MICRO-PROCESSING OF AMORPHOUS AND PARTIALLY CRYSTALLINE Cu45Zr48AI7 ALLOY
}

\author{
S.N. Aqida, D. Brabazon, S. Naher \\ Materials Processing Research Centre, Dublin City University, Dublin 9, Ireland \\ Zs. Kovacs, D. J. Browne \\ School of Electrical, Electronic and Mechanical Engineering, University College Dublin, Belfield, \\ Dublin 4, Ireland \\ e-mail: syarifah.syedahmad2@mail.dcu.ie
}

\begin{abstract}
This paper presents a microstructural study of laser micro-processed high purity Cu45Zr48Al7 alloys prepared by arc melting and Cu-mould casting. Micro-processing of the Cu45Zr48Al7 alloy was performed using a Rofin DC-015 diffusion-cooled $\mathrm{CO}_{2}$ slab laser system with $10.6 \mu \mathrm{m}$ wavelength. The laser was defocused to a spot size of $0.2 \mathrm{~mm}$ on the sample surface. The laser parameters were set to give 300 and $350 \mathrm{~W}$ peak power, $30 \%$ duty cycle and a $3000 \mathrm{~Hz}$ laser pulse repetition frequency (PRF). The PRF and duty cycle resulted a 0.1 ms pulse duration. About 100 micrometer wide channels were scribed on the surfaces of disk shaped amorphous and partially crystalline samples at traverse speeds of 500 and $5000 \mathrm{~mm} / \mathrm{min}$. These channels were analysed using scanning electron microscopy (SEM) and 2D stylus profilometry. The metallographic study and profile of these processed regions are discussed in terms of the applied laser processing parameters. The SEM micrographs showed that striation marks developed at the edge and inside these regions as a result of the laser processing. Grain formation occurred with the processed regions for processing traverse speeds of $500 \mathrm{~mm} / \mathrm{min}$ in the partially crystalline samples. For the amorphous structure, channel widths of $149.6 \mu \mathrm{m}, 102.2 \mu \mathrm{m}$ and $77.4 \mu \mathrm{m}$ were measured. Using the same processing parameters, channel widths of $158.4 \mu \mathrm{m}, 122.0 \mu \mathrm{m}$ and $91.2 \mu \mathrm{m}$ were measured on the partially crystalline alloy surface. The scribed regions showed a maximum depth of $1.4 \mu \mathrm{m}$ and interesting height increases above the original sample surface height of $2 \mu \mathrm{m}$ on the amorphous sample. Micro-segregation was recorded on the samples surfaces at processing parameters of $300 \mathrm{~W}$ and $7.20 \mathrm{~ms}$ exposure time in both the amorphous and crystalline samples. The results from this work showed that micro-scale features can be produced on the surface of amorphous $\mathrm{Cu}-\mathrm{Zr}-\mathrm{Al}$ alloys by $\mathrm{CO}_{2}$ laser processing.
\end{abstract}

PACS 87.85.Va $\cdot 64.70 . \mathrm{pe} \cdot 68.37 . \mathrm{Hk}$

\subsection{Introduction}

In many applications, amorphous metallic alloy or bulk metallic glass (BMG) is potential for replacement of conventional engineering materials like metals and polymers. The BMG materials exhibited better mechanical and physical properties compared to the other crystalline metallic alloys. Additionally, the metallic glasses are more resistant to fracture than covalent glasses or ceramics. It has high hardness and also provides a combination of metallic high strength with elasticity as high as that of polymers [1].

Casting is the most typical method in mass production of BMG which capable of resulting in acceptable dimension accuracy. However, secondary process like machining is vital to deal with stringent dimensional accuracy and surface roughness requirements [2]. In conventional turning and drilling processes, low thermal conductivity of BMG leads to high temperatures generation during chips machining [2]. While producing amorphous alloy materials is challenging, the conventional contact machining has drawback with the cutting tools coating suitability on BMG materials [2]. Recent works on non contact micro-machining of BMG was later done using micro-electro-discharge machining (MEDM) to produce micro-holes [3]. In micromachining of BMG, the heat generated is difficult to diffuse into the base material, which causes large heat affected zone [3].

It is difficult to manufacture micro or nano-size features in crystalline metallic structures, due to the presence of grains. BMG is homogeneous and applicable for nano-scale geometries [4]. Therefore, amorphous metallic structures are becoming more popular for this purpose. Recent attempts of BMG application in micro-scale are precision spur gear, wheel like micro-components, and moulds for aspheric lens fabrication [5-7]. Although, there are huge potential of manufacturing micro and nano-size features in BMGs, there are only a few application currently focusing on this area. This work is significant to expand the 
knowledge on processing micro-features and micro-channels on amorphous alloys. In this paper the effects of laser parameter settings on amorphous and partially crystalline $\mathrm{Cu}-\mathrm{Zr}-\mathrm{Al}$ alloy microstructures were investigated.

\subsection{Experimental}

Bulk metallic glass rods of $\mathrm{Cu} 45 \mathrm{Zr} 48 \mathrm{Al} 7$ composition were produced by arc melting the high purity components and $\mathrm{Cu}$ mould casting the ingot from liquid state. Samples of $5 \mathrm{~mm}$ diameter and $4 \mathrm{~mm}$ thickness were cut from the as-cast rods and were processed and examined in this study. X-ray diffraction patterns of the samples were recorded using a Bruker D8 XRD system with $\mathrm{Cu} K \alpha(\lambda=$ $1.5405 \AA$ ) radiation. The diffraction patterns were recorded in the $2 \theta$ range of 20 to $80^{\circ}$. Samples were mounted in Bakelite and polished before processing to allow clear difference in surface microstructure to be identified. The flat $5 \mathrm{~mm}$ diameter surfaces were laser processed by a single pass of the sample across its diameter beneath the pulsing laser beam. The sample surface was held perpendicular to the laser beam firing direction during this translation. $\mathrm{A} \mathrm{CO}_{2}$ laser with a defocused circular spot diameter of $0.2 \mathrm{~mm}$ on the sample surface was used. The beam quality was TEMoo. The PRF and duty cycle were constant at $3000 \mathrm{~Hz}$ and 30\% respectively for

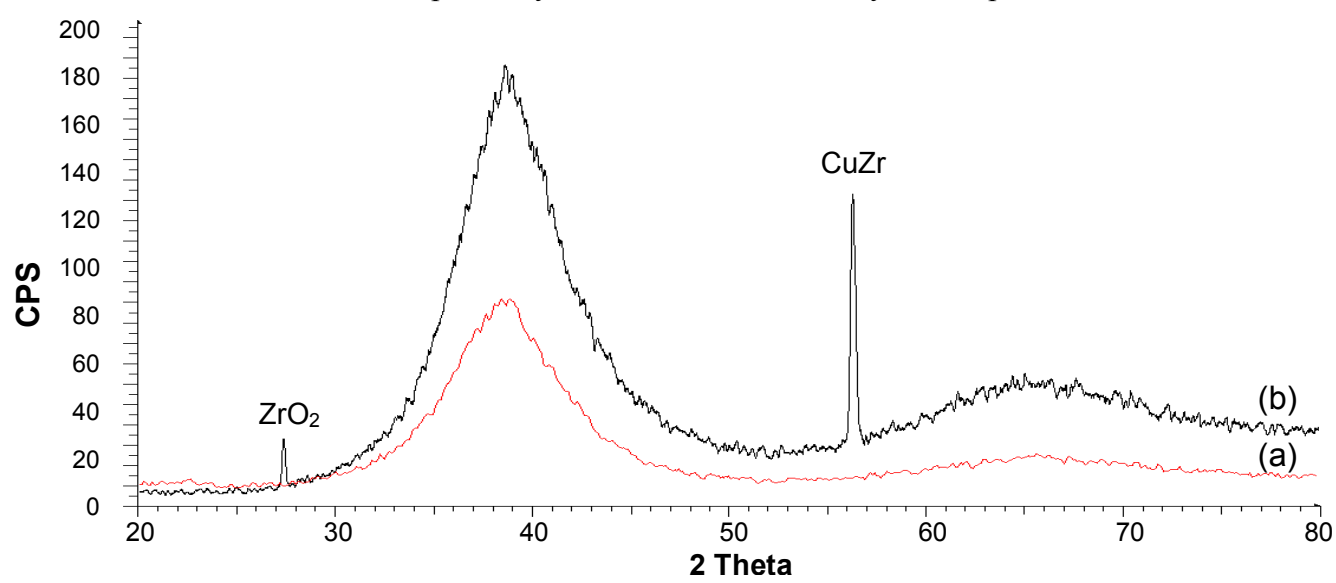

Figure 1: XRD patterns of (a) amorphous and (b) partially crystalline $\mathrm{Cu}-\mathrm{Zr}-\mathrm{Al}$ alloy.

Figure 2 shows the SEM micrographs of micro-channels machined on the sample surface at the three different laser parameter settings for both the fully amorphous and the partially crystalline samples. The average width of micro-channels 1 on the amorphous alloy was $150 \mu \mathrm{m}$ as shown in Figure 2(a). The widths of the micro-channels 2 and 3 on the amorphous alloy were measured as $102 \mu \mathrm{m}$ and $78 \mu \mathrm{m}$ respectively (see Figure 2(b) and (c)). At the higher exposure time for microchannel 1, a wider heat affected region and all experiments. The scribed line (microchannel 1) was processed at $300 \mathrm{~W}$ laser power and $500 \mathrm{~mm} / \mathrm{min}$ to achieve $0.03 \mathrm{~J}$ pulse energy and exposure time of $7.20 \mathrm{~ms}$ respectively. For the second case (microchannel 2), the laser power was set at $350 \mathrm{~W}$ to provide $0.035 \mathrm{~J}$ pulse energy and traverse speed was set at $5000 \mathrm{~mm} / \mathrm{min}$. For the third case (micro-channel 3) was processed at 300 $\mathrm{W}$ laser power and $5000 \mathrm{~mm} / \mathrm{min}$. From the $5000 \mathrm{~mm} / \mathrm{min}$ traverse speed, a shorter exposure time of $0.72 \mathrm{~ms}$ was achieved. These parameter settings were chosen to produce rapid melting along lines (micro-channels) with of about 100 micrometer width. Flowing argon gas was applied during processing at a pressure of one bar. The depths for all microchannels were measured using a 2D TR200 stylus profilometer integrated with TimeSurf software for data acquisition. The processed surface was examined with an EVO-LS15 Scanning Electron Microscope (SEM).

\subsection{Results and Discussion}

Figure 1 shows the XRD pattern oftwo as-cast sample disks. The broad maxima in Figure 1(a) indicate the existence of amorphous phase in the cast sample. The partially crystalline pattern in Figure 1(b) shows, the broad maxima were also detected along with $\mathrm{CuZr}$ and $\mathrm{ZrO}_{2}$ crystalline peaks. 
amorphous and partially crystalline samples exhibited striation marks at the edges and inside the micro-channel. Coarse striation marks perpendicular to the micro-channels were visible at the edges while fine striation marks found inside the channels pointing in the direction of processing. More striation marks were observed in micro-channel 1 compared to the other two channels. Interestingly, a strong contrast indicating the presence of micro-
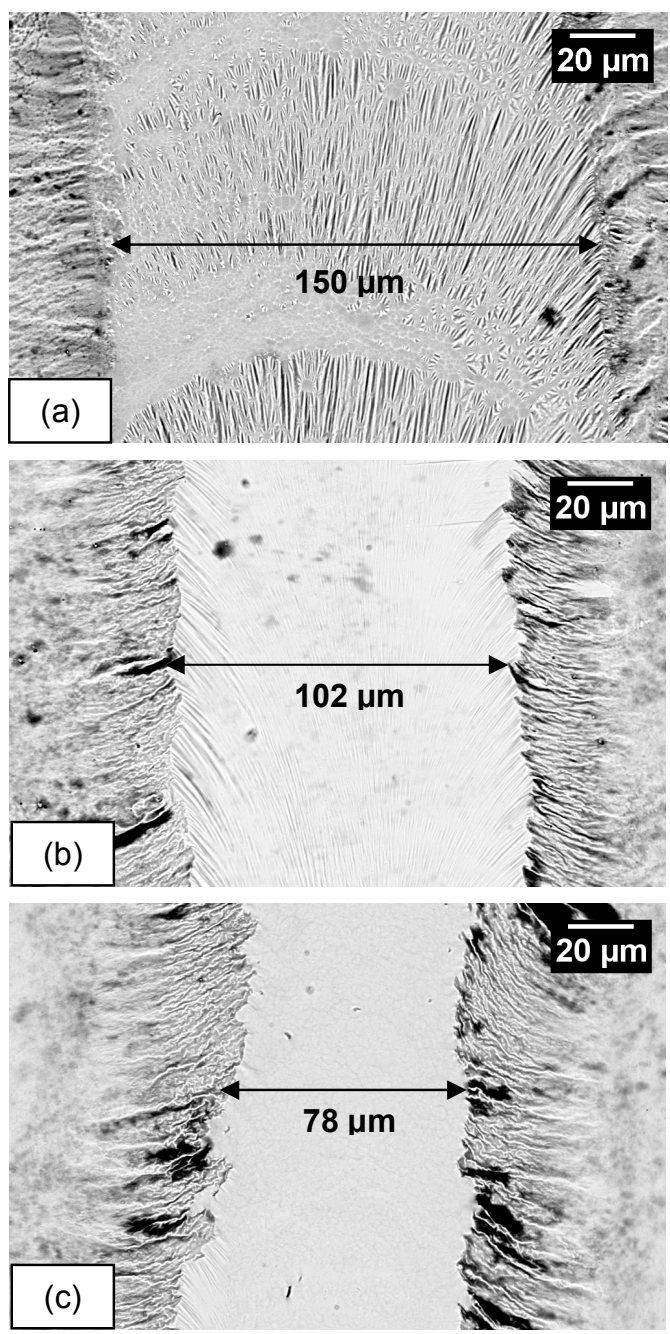

Figure 2: SEM micrographs showing width of
on amorphous $\mathrm{Cu}-\mathrm{Zr}-\mathrm{Al}(\mathrm{a}),(\mathrm{b})$ and (c)
The surface troughs measured in both between 0.8 to $1.4 \mu \mathrm{m}$ deep. Figure 4 shows the $2 \mathrm{D}$ profile measured across micro-channels of the amorphous $\mathrm{Cu}-\mathrm{Zr}-\mathrm{Al}$ alloy sample. The maximum depth of the channel measured was approximately $1.4 \mu \mathrm{m}$. Increase of material volume was observed in the middle of the channel due to either volume conservation or phase change during laser processing. grains was also found in the partially crystalline sample (in micro-channel 1). Figure 3(a) shows a higher magnification SEM micrograph of the structure shown in Figure 2(d). Grains within a size range of 1 to $3 \mu \mathrm{m}$ were developed between the striation marks. Similar grains were not found in the other 2 channels; see Figure 3(b) for comparison which represents a high magnification micrograph of Figure 2(f).
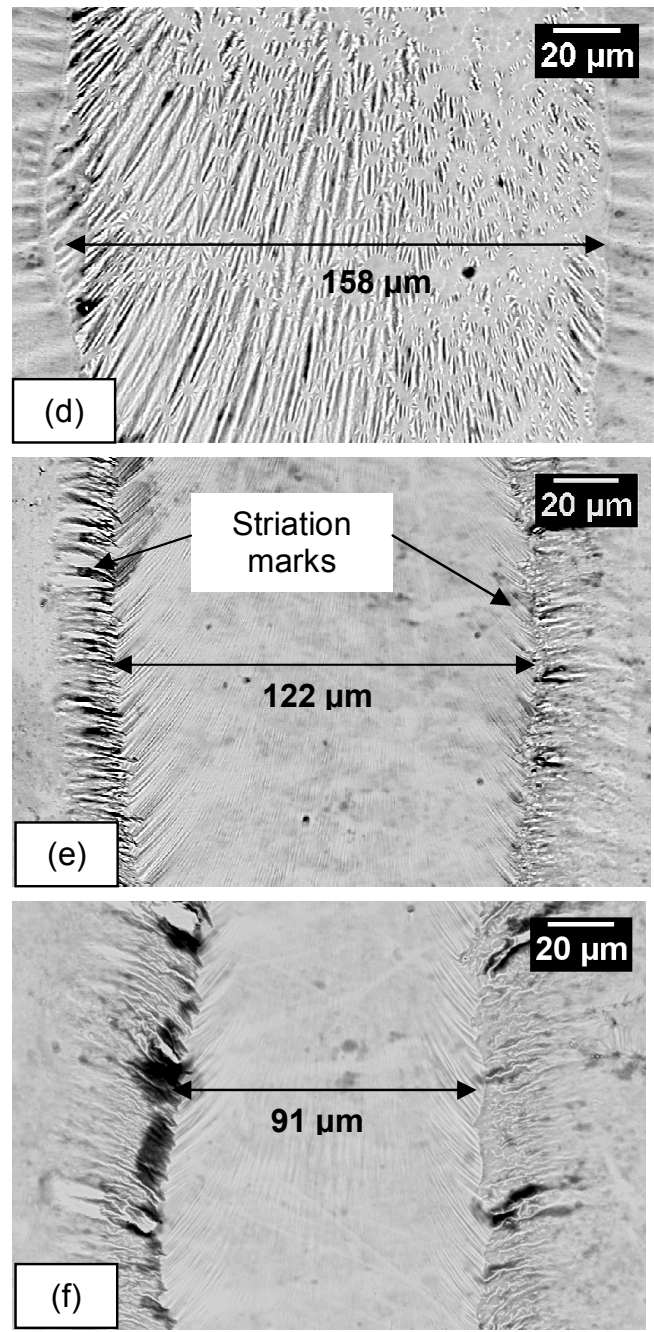
heat flux to the surrounding area and into the surface. Less difference was noticed with respect to feature depth and height between these materials. Striation mark formation at the channel edges was most likely due to thermal strains occurring in the material during rapid cooling from the millisecond exposure time frames. The large energy density from microchannel 1 processing conditions would have caused slower cooling rates within the channel surface. The exposure time for channel 1 was $7.20 \mathrm{~ms}$ which is ten times higher than for channel 2 and 3 processing conditions.

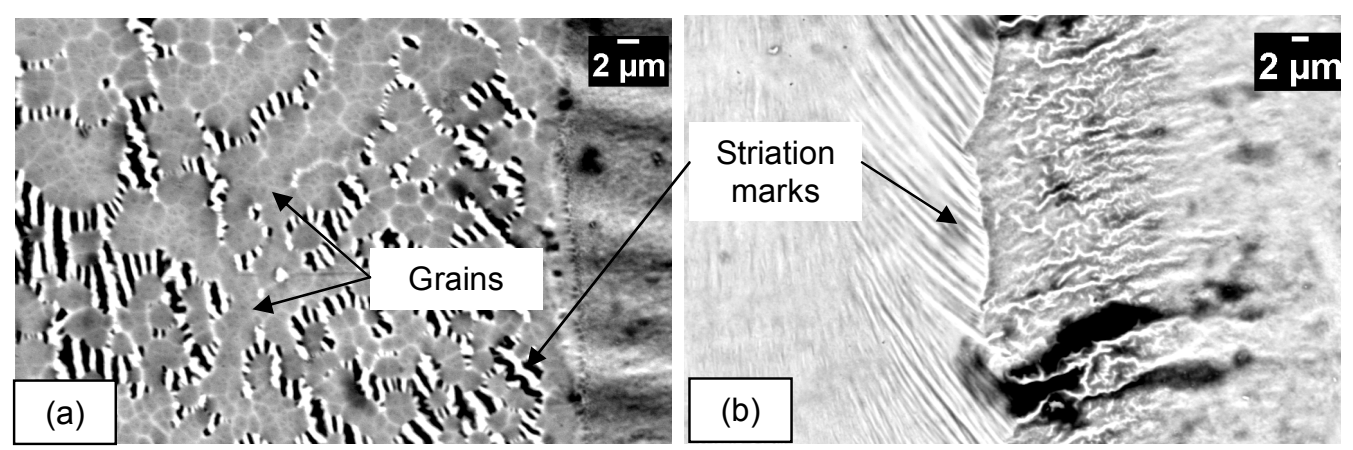

Figure 3: Striation marks for partially crystalline $\mathrm{Cu}-\mathrm{Zr}-\mathrm{Al}$ alloy in (a) line 1 with evidence of micro-grain formation and (b) line 2 without evidence of micro-grains.

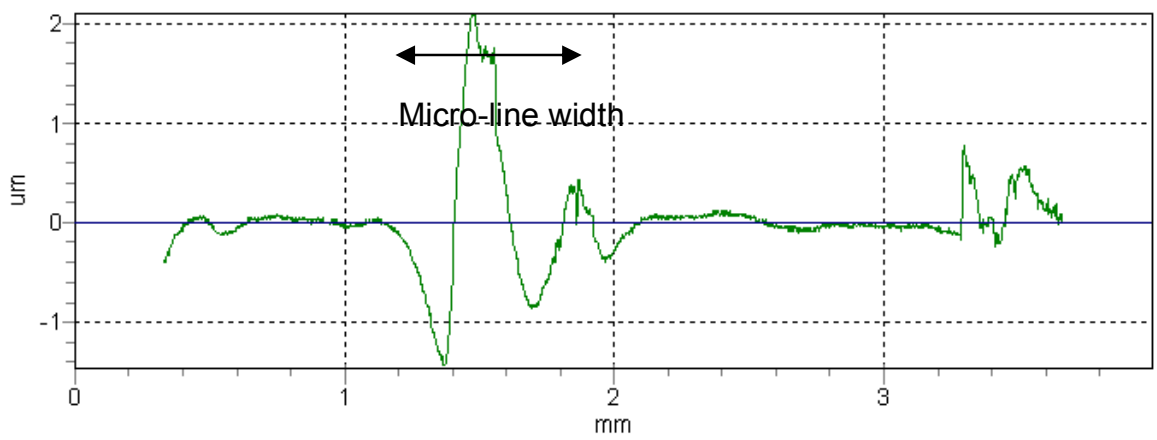

Figure 4: $2 \mathrm{D}$ profile across line 2 of amorphous $\mathrm{Cu}-\mathrm{Zr}-\mathrm{Al}$ alloy.

\subsection{Conclusion}

The results from this work showed that microscale channel and features can be produced on the surface of amorphous $\mathrm{Cu}-\mathrm{Zr}-\mathrm{Al}$ alloy. A range of channel depths from 0.8 to $1.4 \mu \mathrm{m}$ were measured in the amorphous and partially crystalline $\mathrm{Cu}-\mathrm{Zr}-\mathrm{Al}$ alloy. The channel widths measured in the amorphous sample were lower than in the partially crystalline channels most likely due to its low thermal conductivity. The laser machining parameters for creating microchannels on amorphous $\mathrm{Cu}-\mathrm{Zr}-\mathrm{Al}$ alloy samples can be controlled to avoid recrystallisation. By using $300 \mathrm{~W}$ of laser power and $7.20 \mathrm{~ms}$ exposure time, the cooling rate was slow enough to form micro-grains from the pre-existing nuclei in channel 1. No micrograins were observed for lines 2 and 3, where the power was set at 300 and $350 \mathrm{~W}$ and exposure time was kept at $0.72 \mathrm{~ms}$. Striations were found to varying degrees in all scribed micro-channels. This could allow for the possibility of increasing wear resistance in industrial engineering components or directing fluid flow in micro-moulding.

\section{Acknowledgements}

The authors are grateful to Enterprise Ireland for providing Commercialisation Fund, Technology Development support to enable manufacture of the BMG rod samples.

\subsection{References}

[1] M. Telford: Materials Today, 36 (2004)

[2] M. Bakkal, A. J. Shih, R. O. Scattergood, C.T. Liu: Scripta Materialia. 50, 583 (2004)

[3] Z. Xingchao, Z. Yong, T. Hao, L. Yong, C. Xiaohua, C. Guoliang: Proc. of HDP'07 (2007)

[4] J. Schroers, T. Nguyen, S. O'Keeffe, A. Desai: Mater. Sci. Eng. A 449-451 898, (2007)

[5] Z. Zhang, J. Xie: Mater. Sci. Eng. A 433, 323 (2006)

[6] J. A. Wert, C. Thomsen, R. D. Jensen, M. Arentoft: J. Mater. Proc. Tech. 209, 1570 (2009)

[7] C. T. Pan, T. T. Wu, Y. T. Liu, Y. Yamagata, J.C. Huang: J. Mater. Proc. Tech. 209, 5014 (2009)

[8] B.D. Cullity, S.R. Stock: Elements of X-Ray Diffraction (Prentice Hall- 2001)

[9] Y. Tian, Z. Q. Li, E. Y. Jiang: Solid State Comm. 149, 1527 (2009). 